KAPL-P-000134

(K98194)

\title{
ANTIMONIDE BASED DEVICES FOR THERMOPHOTOVOLTAIC APPLICATIONS
}

C. W. Hitchcock, G. W. Charache

December 1998

\section{NOTICE}

This report was prepared as an account of work sponsored by the United States Government. Neither the United States, nor the United States Department of Energy, nor any of their employees, nor any of their contractors, subcontractors, or their employees, makes any warranty, express or implied, or assumes any legal liability or responsibility for the accuracy, completeness or usefulness of any information, apparatus, product or process disclosed, or represents that its use would not infringe privately owned rights.

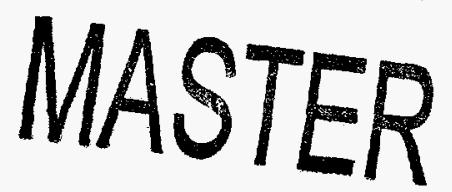

\section{DISTRBUTION OF THS DOCUMENT iS UNLIMTEE}

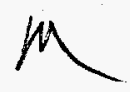

KAPL ATOMIC POWER LABORATORY

SCHENECTADY, NEW YORK 13401

Operated for the U. S. Department of Energy

by KAPL, Inc. a Lockheed Martin company 


\section{DISCLAIMER}

This report was prepared as an account of work sponsored by an agency of the United States Government. Neither the United States Government nor any agency thereof, nor any of their employees, makes any warranty, express or implied, or assumes any legal liability or responsibility for the accuracy, completeness, or usefulness of any information, apparatus, product, or process disclosed, or represents that its use would not infringe privately owned rights. Reference herein to any specific commercial product, process, or service by trade name, trademark, manufacturer, or otherwise does not necessarily constitute or imply its endorsement, recommendation, or favoring by the United States Government or any agency thereof. The views and opinions of authors expressed herein do not necessarily state or reflect those of the United States Government or any agency thereof. 


\section{DISCLAIMER}

Portions of this document may be illegible in electronic image products. Images are produced from the best available original document. 


\title{
Antimonide Based Devices for Thermophotovoltaic Applications
}

\author{
C.W. Hitchcock, R.J. Gutmann, J.M. Borrego, I.B. Bhat \\ Center for Integrated Electronics and Electronics Manufacturing \\ Rensselaer Polytechnic Institute, Troy, NY 12180-3590 \\ G.W. Charache \\ Lockheed Martin, Inc., Schenectady, NY 12301
}

\begin{abstract}
Thermophotovoltaic (TPV) devices have been fabricated using epitaxial ternary and quaternary layers grown on GaSb substrates. GaInSb ternary devices were grown by metalorganic vapor phase epitaxy (MOVPE) with buffer layers to accommodate the lattice mismatch, and GaInAsSb lattice-matched quaternaries were grown by MOVPE. Improved devices are obtained when optical absorption occurs in the p-layer due to the longer minority carrier diffusion length. Thick emitter $\mathrm{p} / \mathrm{n}$ devices are limited by surface recombination, with highest quantum efficiency and lowest dark current being achieved with epitaxially grown surface passivation layers on lattice-matched MOVPE quaternaries. Thin emitter/thick base, $n / p$ devices are very promising, but require improved shallow high-quality n-type ohmic contacts. Diffused junction devices using quasi-binary substrates offer the possibility of good performance and low manufacturing cost.
\end{abstract}

\section{Introduction}

Thermophotovoltaic (TPV) devices are being explored for a variety of terrestrial and space applications [1-4]. The systems approach has been to use silicon devices matched to selective emitters or design low-band gap compound semiconductor cells matched to blackbody emitters. This paper presents results of epitaxial devices on GaSb substrates for TPV applications requiring band gap energies near $0.55 \mathrm{eV}$, focusing on electrical parameters achieved with different epitaxial growth techniques and alternative device structures. 


\section{Device Structures and Epitaxial Techniques}

In order to maximize both the efficiency and the power density of TPV devices, we examined device structures which minimize saturation current density, allowing devices to be operated at high forward bias without significant dark current loss, while maintaining high collection efficiency of photogenerated carriers. The material properties required to achieve these device goals are maximum minority carrier diffusion length, minimum minority carrier recombination at device surfaces, and optimum device doping profiles. The generic device structure is shown in figure 1, with the key parameters of 5 device types presented in table 1.

In order to achieve the required characteristics, we considered three different device structures. The first structure consists of a thin p-type emitter and a thick n-type base (device type 1). The majority of the photon absorption occurs in the n-type base; therefore, the hole diffusion length in the base is of critical importance. The high doping required to minimize series resistance, along with the close proximity of the front surface, produces high minority carrier losses, and the efficiency associated with the emitter is low. In our experience, obtaining a suitably large minority carrier diffusion length in the n-type base has been a problem due to: (1) the relatively low hole mobility in this region, (2) the potential for deep level defects associated with the Te dopant [5], and (3) higher Auger recombination rates in n-type material [6].

The second device structure is the thick p-emitter, thin n-base configuration (device types 2-4). Here all of the absorption takes place in the emitter, so the minority carrier properties of the base are important only for reducing the dark current. The large width of the emitter allows a reasonably low doping without introducing excessive series resistance, and the large minority electron mobility in the absorption region is an advantage. The principal disadvantage is that most of the absorption takes place close to the device front surface. Unless the front surface is a very good minority carrier mirror, surface losses will dominate. In order to achieve a better minority carrier mirror, surface passivations have been attempted by growing epitaxial layers of larger bandgap on the front surface. The thick p-emitter structure with surface passivation has been established as the baseline device for high-performance $0.55 \mathrm{eV}$ antimonide-based TPV devices.

The third device structure is the thin n-emitter, thick $\mathrm{p}$-base configuration (device type 5). Here, losses due to absorption in the heavily doped, surface 
n-emitter will still be present, but the emitter can be shallower and/or less heavily doped due to the higher mobility of the majority electrons in the lateral current flow to the front contact. In the p-type base, efficient minority carrier transport to the collection junction can occur without the losses due to a poor surface. The principal disadvantage of this device design is the difficulty associated with contacting a thin n-type layer. The anneal required for ohmic contacts to $\mathrm{n}$-type material generally produces a reaction which extends through the emitter and short circuits the device junction. Shallow n-type contacts would permit optical absorption in the p-type base, resulting in high quantum efficiency devices without surface passivation.

The epitaxial growth techniques for the ternary and quaternary device structures are described elsewhere [7].

\section{Device Fabrication Techniques}

In order to produce TPV devices, conventional semiconductor processing techniques were employed. Initially, the samples were cleaned using acetone, methanol, and isopropanol to remove organic contaminants, followed by a brief immersion in 20:1 hydrofluoric acid to remove surface oxide. Immediately following the HF immersion, the samples were placed under vacuum and a blanket contact metal was applied to the sample back surface by ebeam evaporation (contact metallizations are described later ). Devices with n-type substrates underwent an anneal after back contact formation. Next photoresist was applied to the front of the sample and patterned using a complex liftoff process described elsewhere [4]. After the photoresist was developed (exposing the areas to be contacted) the samples were cleaned with a 20:1 HF immersion and placed immediately under vacuum. The front grid metal was deposited by e-beam evaporation, followed by completion of the liftoff process. The devices then underwent another photolithography process to isolate the nominally $1 \mathrm{~cm}^{2}$ cells; the active areas were protected with a thin layer of photoresist and the emitter epilayers outside the active region were etched away in an $\mathrm{HCl}: \mathrm{H}_{2} \mathrm{O}_{2}: \mathrm{NaK}$ Tartrate solution (66mL:18mL:24g in $1 \mathrm{~L}$ of solution).

For p-type contacts, $200 \mathrm{~nm}$ of gold were deposited and then capped with 1 to 2 microns of silver. The gold layer was chosen to produce a good interface while the silver layer provided low resistivity bulk and a good surface for probing. No contact anneal was required for p-type contacts, as the 
Fermi level is pinned near the valence band of these semiconductors, regardless of the work function of the contact metal [8], so that contacts to p-type materials are generally ohmic as deposited and produce specific contact resistances between $10^{-4}$ and $10^{-5} \Omega \mathrm{cm}^{2}$ as measured by the method of Cox and Strack $[9,10]$. While lower specific contact resistances have been obtained with other surface cleans and post-deposition anneals [11], $10^{-4} \Omega \mathrm{cm}^{2}$ has only a minor effect on contact grid design.

For n-type contacts to bulk materials, an evaporation of $10 \mathrm{~nm}$ tin followed by $200 \mathrm{~nm}$ of gold was employed [12], with the unalloyed contact being nonohmic. The devices were alloyed at $350^{\circ} \mathrm{C}$ for 5 seconds, with a resultant specific contact resistance between $10^{-4}$ and $10^{-5} \Omega \mathrm{cm}^{2}$.

The contacting method used for bulk n-type layers has not been successful for shallow n-type contacts. During the anneal, a reaction occurs between the gold, tin, and semiconductor. The gold surface turns silvery gray during the anneal. Electrically, p-n diodes with thin n-type emitters contacted with the bulk- $n$ metallization become short circuits during the anneal. Physically, a reaction occurs between the metals and the semiconductor material so that all of the n-type layer is consumed in some places, and the metal contacts the p-type layer below.

A nonshorting contact to a thin n-type emitter requires a reduced reaction between the metal and the semiconductor. A titanium layer at least $50 \mathrm{~nm}$ thick inhibits such a reaction, so that other metals can be deposited subsequently without affecting the titanium semiconductor junction. A structure of $10 \mathrm{~nm}$ of tin followed by $150 \mathrm{~nm}$ of titanium, $50 \mathrm{~nm}$ of gold, and $1-2 \mu \mathrm{m}$ of silver annealed at $350^{\circ} \mathrm{C}$ for $5 s$ produced functional devices when applied to a reasonably thick $(9 \mu \mathrm{m})$ n-emitter. Subsequent post-contact emitter etching in concentrated $\left(\mathrm{NH}_{4}\right)_{2} \mathrm{~S}$ solution thins the emitter at $10 \mathrm{~nm}$ per minute allowing an emitter to be thinned to the optimal device width from a thicker initial width chosen from processing considerations.

\section{Characterization Techniques}

In order to determine the underlying physics of the semiconductor junctions, $\mathrm{I}-\mathrm{V}$ and quantum efficiency characteristics were measured. Due to the high current, low voltage nature of thermophotovoltaic devices, Kelvin contacting methods were used for both front and rear contacts.

I-V measurements taken in the forward direction agreed with the expected 
device behavior using the following relationship, consistent with classical Schockley injection theory:

$$
I=I_{s} \cdot\left[\exp \left(\frac{q\left(V-I \cdot R_{e}\right)}{n k T}\right)-1\right]+\frac{V-I \cdot R_{e}}{R_{u}}-I_{L}
$$

where $R_{e}$ and $R_{u}$ are parasitic series and shunt resistances, respectively. These resistances could usually be neglected in the analysis of the illuminated characteristics of high quality devices. Measurements were taken on a temperature controlled stage over the range from $-15^{\circ} \mathrm{C}$ to $115^{\circ} \mathrm{C}$, and equation 1 remained valid over this range. Curve fitting techniques were used to extract relevant parameters from device measurement curves.

Quantum efficiency (QE) measurements were used to determine device layer diffusion coefficients and surface properties. Since the material absorption coefficient of $\mathrm{GaSb}$ is known reasonably well as a function of wavelength $[13,14]$, and the absorption coefficients of related ternaries and quarternaries can be estimated with reasonable accuracy [15]; a theoretical QE curve can be simulated for a device with known emitter and base thicknesses and assumed minority carrier diffusion lengths and surface recombination velocities. The theoretical curve can be compared to the empirical curve, and the unknown parameters (diffusion lengths and surface recombination velocities) can be adjusted to produce a fit. The curve fit obtained is generally unique and a reasonable value of the unknown parameters can be extracted (or in some cases a lower or upper bound).

\section{Results and Discussion}

Figures 2 and 3 present external QE of the 5 device types. The experimental curves (broken curves) are presented along with theoretical curves (solid curves) fit to the data. Diffusion lengths (L) and surface recombination velocities (S) can be deduced from these fits by using a drift diffusion model [16], with fixed values for the known parameters such as device layer widths (W) and absorption coefficients, and varying the unknown parameters to achieve the best fit.

Figure 2 presents curves for devices with GaInAsSb quaternary active layers. The lower curve presents a device with a very lossy emitter. Qualitatively, a triangular curve which peaks at the bandgap wavelength and decreases to zero near $500 \mathrm{~nm}$ is indicative of a poor emitter front surface 
for a thick emitter device. Quantitatively, although the slope of the curve allows us to state that most of the loss is at the front surface of the emitter, a finite bulk recombination component could be present but masked by the large surface loss. We present a lower bound for the corresponding bulk diffusion length. The upper curve of figure 2 presents a device in all respects identical to that of the lower curve, except that the front surface has been capped with $100 \mathrm{~nm}$ of $\mathrm{AlGaAsSb}$. This cap layer results in a considerable improvement in external quantum efficiency, with the characteristics peaking at 65 percent and remaining more constant from $1200 \mathrm{~nm}$ to $2100 \mathrm{~nm}$. For the capped device, the surface recombination loss mechanism has been reduced to the point that it is too small to be detected using the curve fit; when the diffusion length in the emitter is assumed greater than 3 microns and the surface recombination velocity is assumed smaller than $5 \times 10^{4} \mathrm{~cm} / \mathrm{s}$ (the parameter range where the external quantum efficiency is unaffected by the specific values assumed), the best fit to the data is obtained. The upper curve of figure 2 is below unity due only to reflection at the air/semiconductor boundary and absorption in the cap layer.

Figure 3 presents curves for devices with ternary (GaInSb) active layers. The lower curve shows the characteristic of a device with a design similar to those of figure 2. For this ternary device a GaSb cap is used which is somewhat effective, as the best curve fit is obtained assuming that bulk recombination loss dominates. However, the bulk emitter recombination rate is higher than for the quaternary device and the ternary device is therefore limited by a shorter emitter minority carrier diffusion length and does not achieve the performance of device type 4 . The upper and middle curves of figure 3 represent device types 1 and 5 respectively. Unlike the other three device types, these devices have thin emitters and thick bases. The design goal of these device structures is to minimize emitter surface effects by absorbing the majority of the photons in the device base region. The QE of device type 1 fails to meet the ideal of device type 4 because the base minority carrier diffusion length is low, and the QE of device type 5 falls even lower due to the fact that the emitter has been made fairly thick for reasons pertaining to device processing and therefore an appreciable fraction of photons are absorbed in the emitter.

Figure 4 presents two QE curves for a single device of type 5. The lower corresponds to a structure almost identical to the device which produced the middle QE curve of figure 3, but with slightly different growth conditions resulting in somewhat different surface properties and bulk lifetimes. The 
upper curve of figure 4 is for the same device after a 60 minute etch in concentrated $\left(\mathrm{NH}_{4}\right)_{2} \mathrm{~S}$ solution resulting in a thinning of the emitter from $0.9 \mu \mathrm{m}$ to $0.3 \mu \mathrm{m}$. Although this device has a poor base diffusion length and exhibits a very low parasitic shunt resistance, the improvement in $\mathrm{QE}$ demonstrates the promise of emitter thinning for fabricating devices with thin n-emitters.

While the QE curves illustrate the relative collection efficiencies of the devices at various wavelengths, they fail to provide information concerning device performance under realistic high-intensity illumination. Figure 8 displays short circuit current density versus open circuit voltage for the devices under study. Improvements in minority carrier diffusion length or surface properties will move a device curve toward the right, achieving a higher open circuit voltage for a given short circuit current and higher overall device effciency. Figure 8 illustrates that devices with surface passivations outperform devices without passivation in terms of open circuit voltage, with the exception of device type 5 which has an open circuit voltage approaching those of the passivated devices (indicating the promise of such a structure). Also note that despite the disappointing QE of device type 3, the GaSb surface passivation has resulted in considerably better open circuit voltage than would have been achieved without passivation.

In order to investigate the nature of the device dark current and the validity of our drift-diffusion conduction model, we have measured I-V curves for several devices over the temperature range from $-15^{\circ} \mathrm{C}$ to $115^{\circ} \mathrm{C}$. As an example, figures 5 and 6 present forward and reverse bias curves for device type 2 at $10^{\circ} \mathrm{C}$ intervals. When device parameters are extracted from the forward bias curves, the saturation current density for forward conduction appears to conform to the classical temperature dependence, as illustrated in figure 7 :

$$
n_{i}^{2} \propto T^{3} \exp \left(\frac{-E_{g}}{k T}\right)
$$

Figure 6 indicates an increase in reverse current with temperature that is prominent only above room temperature, possibly indicating a transition between two reverse conduction mechanisms.

Besides the promising n-on-p structure, recent research results [17] on the growth of quasi-binary boules with $0.55 \mathrm{eV}$ band gap offer the possibility of diffused-junction devices, either thick p-on-n (Zn diffusion) or thin-tomedium n-on-p (Te diffusion) structures. While such devices are yet to be demonstrated, the microstructural [17] and electro-optical [18] properties of 
the quasi-binary substrates are very attractive.

\section{Summary}

The two most promising device structure for antimonide-based TPV devices are either thick p-emitter, $\mathbf{n}$-base devices with well passivated front surfaces (minority carrier mirrors to reduce the effective surface recombination velocity) or thin n-emitter, thick p-base devices with non-shorting ohmic contacts.

Two key performance metrics have been used in this work, namely quantum efficiency open circuit voltage versus short circuit current. Both high quantum efficiency and high open circuit voltage are needed to achieve maximum TPV device performance (i.e., high electrical power density and high optical-to-electrical conversion efficiency). The quantum efficiency combined with a curve of short-circuit current versus open-circuit voltage (obtained with different optical intensities) provides the relevant information for TPV cells.

These antimonide TPV cell technologies should provide power densities in the watt $/ \mathrm{cm}^{2}$ range with reasonable conversion efficiency and be attractive for TPV system applications. Diffused junction cells with quasi-binary substrates offer a lower manufacturing cost, although a full performance comparison needs to be established.

\section{Acknowledgements}

The quaternary and ternary epitaxial material was grown by Dr. Christine Wang and Dr. Hassan Ehsani of Lincoln Laboratories and Rensselaer, respectively. 


\section{References}

[1] H. Ehsani, I. Bhat, C. Hitchcock, J. Borrego, and R. Gutmann, "Characteristics of GaSb and GaInSb Layers Grown by Metalorganic Vapor Phase Epitaxy", Second NREL Conference on Thermophotovoltaic Generation of Electricity, AIP Proceedings 351, pages 423-433, 1995.

[2] H. Ehsani, I. Bhat, C. Hitchcock, and R. Gutmann, "Growth and Characterization of $\mathrm{In}_{0.2} \mathrm{Ga}_{0.8} \mathrm{Sb}$ Device Structures Using Metalorganic Vapor Phase Epitaxy", Third NREL Conference on Thermophotovoltaic Generation of Electricity, AIP Proceedings 401, pages 65-74, 1997.

[3] C. Wang, H. Choi, G. Turner, D. Spears, and M. Manfra, "LatticeMatched Epitaxial GaInAsSb/GaSb Thermophotovoltaic Devices", Third NREL Conference on Thermophotovoltaic Generation of Electricity, AIP Proceedings 401, pages 75-87, 1997.

[4] C. Hitchcock, R. Gutmann, J. Borrego, H. Ehsani, I. Bhat, M. Freeman, and G. Charache, "GaInSb and GaInAsSb Thermophotovoltaic Device Fabrication and Characterization", Third NREL Conference on Thermophotovoltaic Generation of Electricity, AIP Proceedings 401, pages 89-103, 1997.

[5] J. Doerschel and U. Geissler, "Characterization of Extended Defects in Highly Te-doped $\langle 111\rangle \mathrm{GaSb}$ Single Crystals Grown by the Czochralski Technique", Journal of Crystal Growth, 121:789-789, 1992.

[6] G. Benz and R. Conradt, "Auger Recombination in GaAs and GaSb", Physical Review B, 16(2):843-855, July 1977.

[7] C. Hitchcock, R. Gutmann, H. Ehsani, I. Bhat, C. Wang, M. Freeman, and G. Charache, "Ternary and Quaternary Antimonide Devices for Thermophotovoltaic Applications", The Ninth International Conference on Metal Organic Vapor Phase Epitaxy, Journal of Crystal Growth, 1998 , to be published.

[8] J. McCaldin, T. McGill, and C. Mead, "Schottky Barriers on Compound Semiconductors: The Role of the Anion", Journal of Vacuum Science and Technology, 13(4):802-806, July/August 1976. 
[9] R. H. Cox and H. Strack, "Ohmic Contacts for GaAs Devices", SolidState Electronics, 10:1213-1218, 1967.

[10] G. P. Carver, J. J. Kopanski, D. B. Novotny, and R. A. Forman, "Specific Contact Resistivity of Metal-Semiconductor Contacts-A New, Accurate Method Linked to Spreading Resistance", IEEE Transactions on Electron Devices, 35(4):489-496, April 1988.

[11] B. Tadayon, C. S. Kyono, M. Fatemi, S. Tadayon, and J. A. Mittereder, "Extremely Low Specific Contact Resistivities for p-type GaSb, Grown by Molecular Beam Epitaxy", Journal of Vacuum Science and Technology B, 13(1):1-3, January/February 1995.

[12] C. H. Heinz, "Ohmic Contacts to p- and n-Type GaSb", International Journal of Electronics, 54(2):247-254, 1983.

[13] D. E. Aspnes and A. A. Studna, "Dielectric Functions and Optical Parameters of $\mathrm{Si}, \mathrm{Ge}, \mathrm{GaP}, \mathrm{GaAs}, \mathrm{GaSb}, \mathrm{InP}$, InAs, and InSb from 1.5 to 6.0 eV", Physical Review B, 27(2):985-1009, January 1983.

[14] R. K. Willardson and A. C. Beer, editors, Semiconductors and Semimetals, volume 3. Academic Press, 1966.

[15] M. J. Zierak, Characterization and Modeling of InGaAs and InGaSb Thermophotovoltaic Cells and Materials, PhD thesis, Rensselaer Polytechnic Institute, 1997.

[16] E. Yang, Microelectronic Devices, pages 363-366. McGraw-Hill Book Company, 1988.

[17] P.S. Dutta, A.G. Ostrogorsky, and R.J. Gutmann, "Bulk Crystal Growth of Antimonide-Based III-V Compounds for TPV Applications", Fourth NREL Conference on Thermophotovoltaic Generation of Electricity, 1998, to be published in AIP Proceedings.

[18] S. Saroop, J.M. Borrego, R.J. Gutmann, P.S. Dutta, A.G. Ostrogorsky, and G. Charache, "RF Photoreflectance Characterization of Binary and Quasi-Binary Substrates for Antimonide-Based TPV Devices", Fourth NREL Conference on Thermophotovoltaic Generation of Electricity, 1998, to be published in AIP Proceedings. 


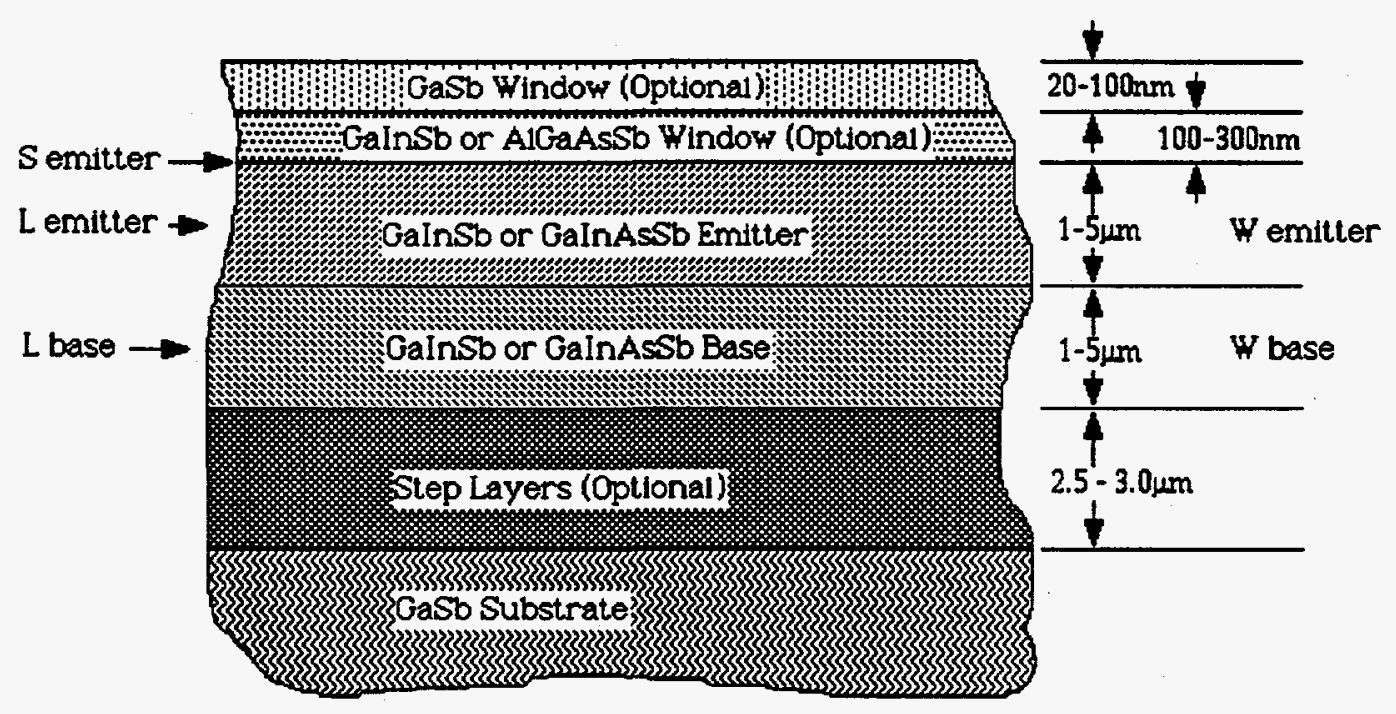

Figure 1: Generic TPV device structure. Critical parameters are W emitter, W base, $\mathrm{S}$ emitter (surface recombination velocity at the emitter top surface), L emitter, and L base (diffusion lengths in emitter and base)

$\begin{array}{ccccccc}\begin{array}{c}\text { device } \\ \text { type }\end{array} & \begin{array}{c}\text { active } \\ \text { layers }\end{array} & \begin{array}{c}\text { emitter } \\ \text { type }\end{array} & \begin{array}{c}\text { emitter } \\ \text { thickness } \\ \text { (W emitter) }\end{array} & \begin{array}{c}\text { base } \\ \text { thickness } \\ \text { (W base) }\end{array} & \text { window } & \begin{array}{c}\text { growth } \\ \text { technique }\end{array} \\ 1 & \text { GaInSb } & \text { thin p } & 0.3 \mu m & 4.5 \mu m & \text { none } & \text { MOVPE } \\ 2 & \text { GaInAsSb } & \text { thick p } & 3 \mu m & 1 \mu m & \text { none } & \text { MOVPE } \\ 3 & \text { GaInSb } & \text { thick p } & 4.5 \mu m & 1 \mu m & \text { GaSb } & \text { MOVPE } \\ 4 & \text { GaInAsSb } & \text { thick p } & 3 \mu m & 1 \mu m & \text { AlGaAsSb } & \text { MOVPE } \\ 5 & \text { GaInSb } & \mathrm{n} & 0.9 / 0.3 \mu m & 5 \mu m & \text { none } & \text { MOVPE }\end{array}$

Table 1: TPV device structure parameters 


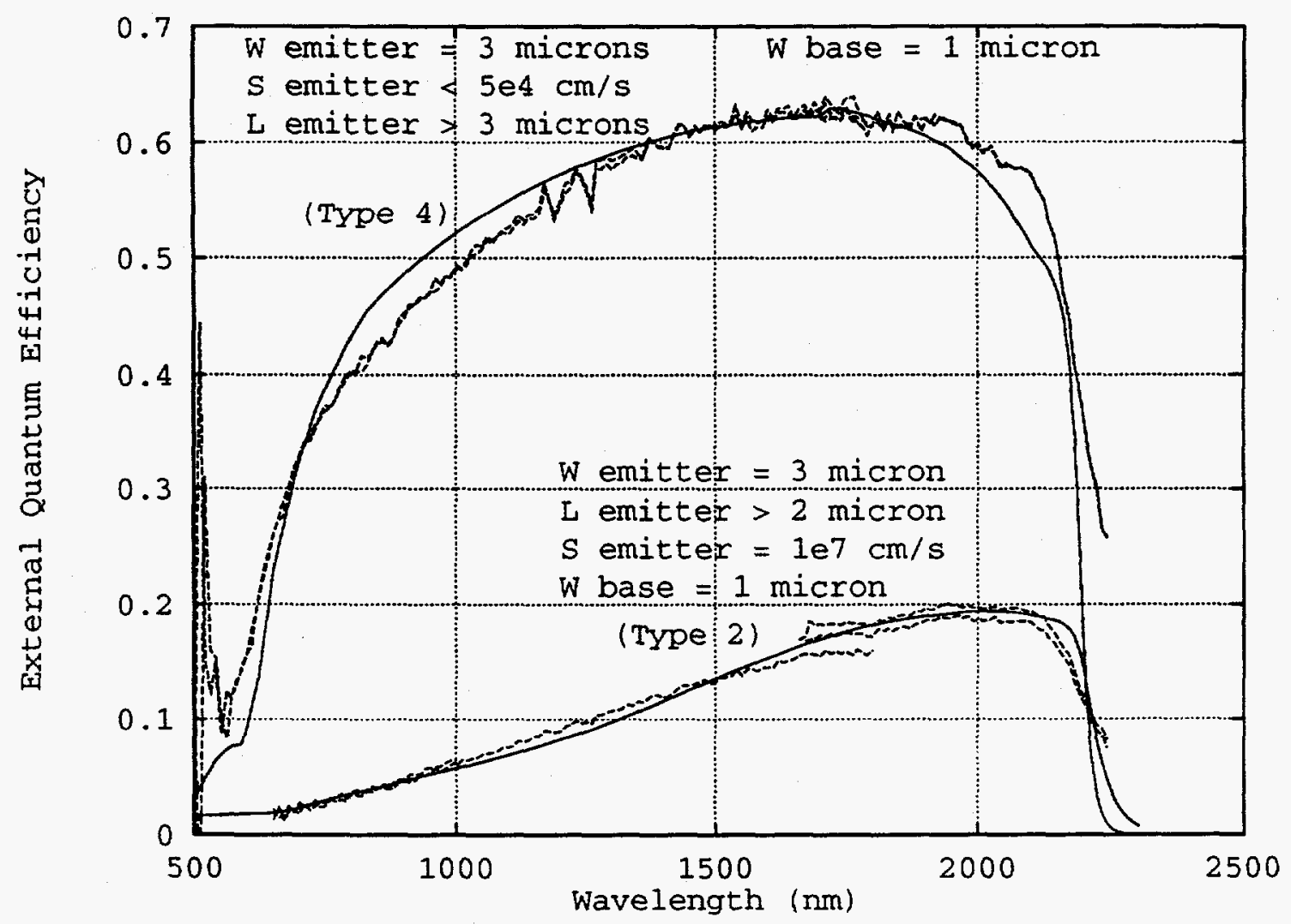

Figure 2: External quantum efficiency of quaternary devices, Upper curve: AlGaAsSb passivation (device type 4), Lower curve: no passivation (device type 2) 


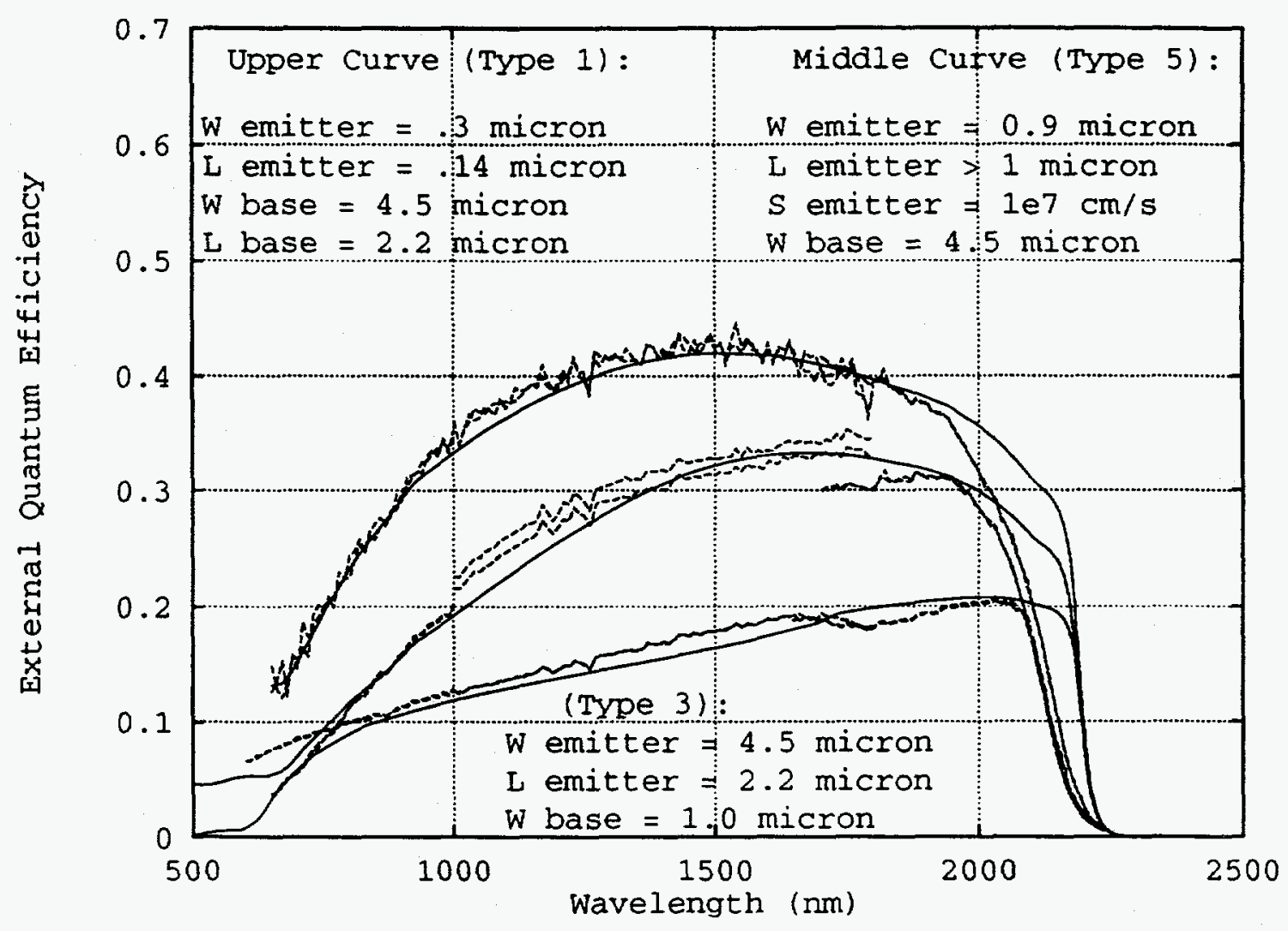

Figure 3: External quantum efficiency of ternary devices, Upper curve: Thin p-emitter device, no passivation (device type 1), Middle curve: N-emitter device, no passivation (device type 5), Lower curve: Thick p-emitter, GaSb passivation (device type 3) 


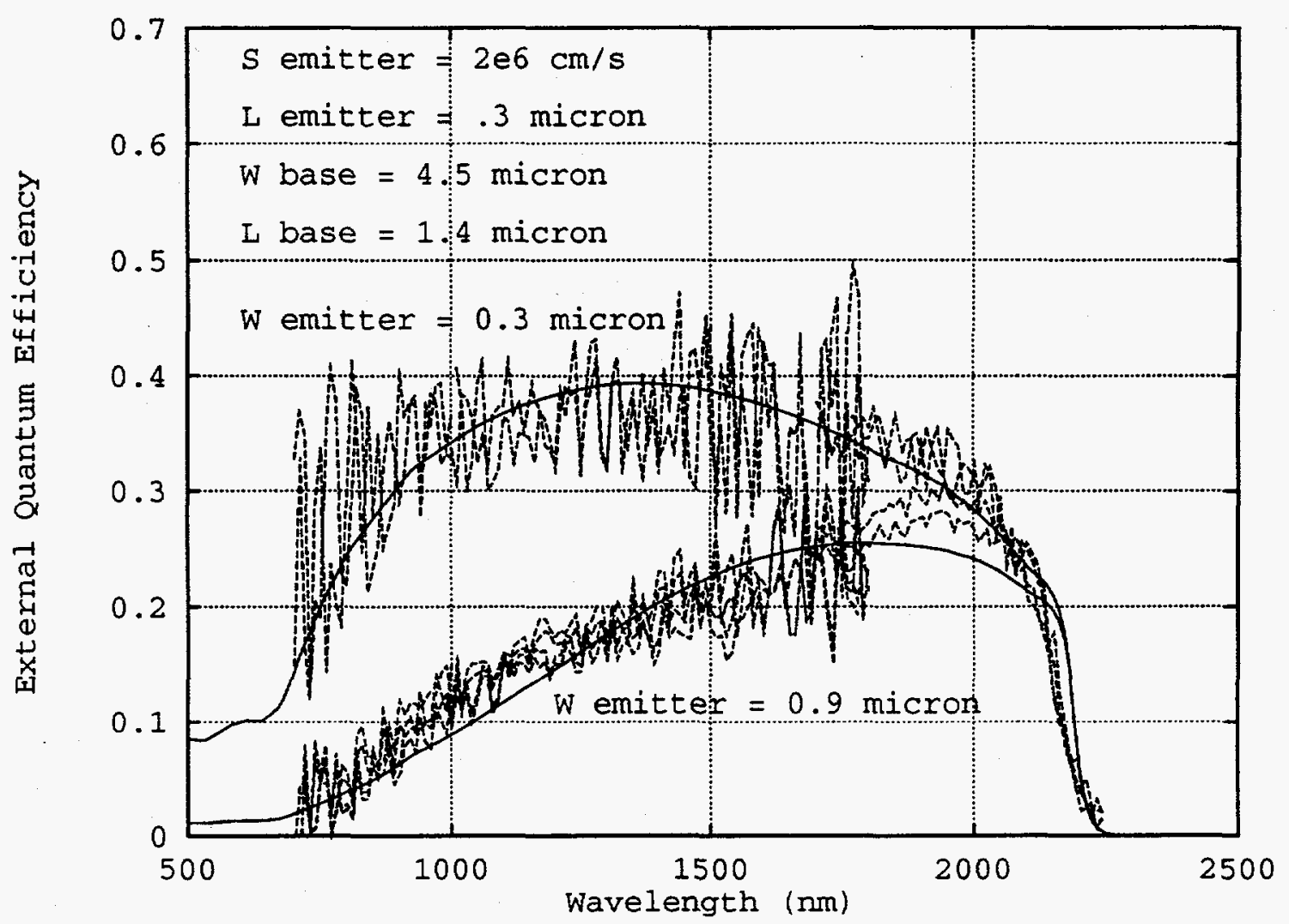

Figure 4: External quantum efficiency before and after etch (device type 5) 


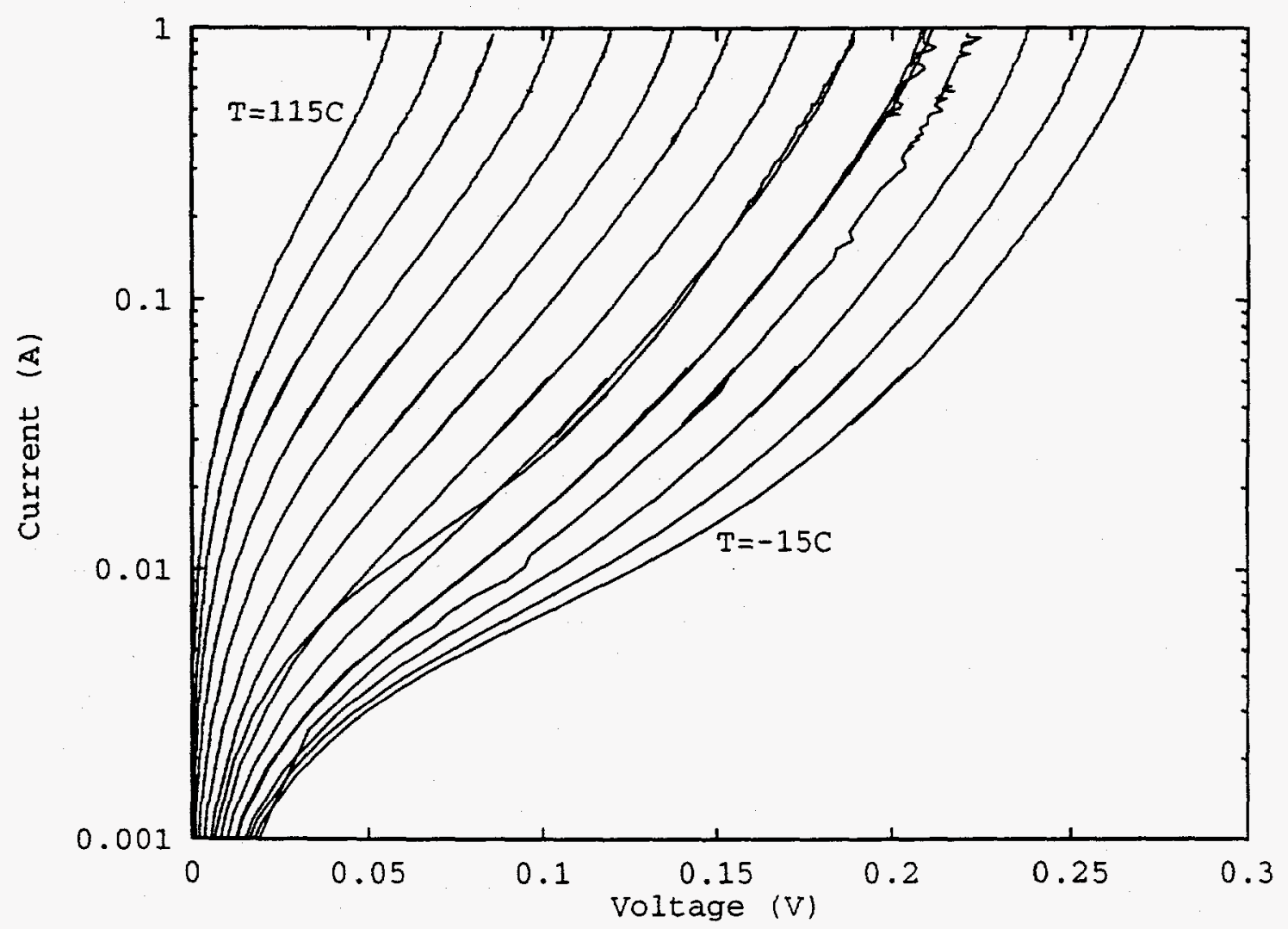

Figure 5: Temperature dependent forward dark IV from $-15^{\circ} \mathrm{C}$ to $115^{\circ} \mathrm{C}$ at $10^{\circ} \mathrm{C}$ increments(device type 2 ) 


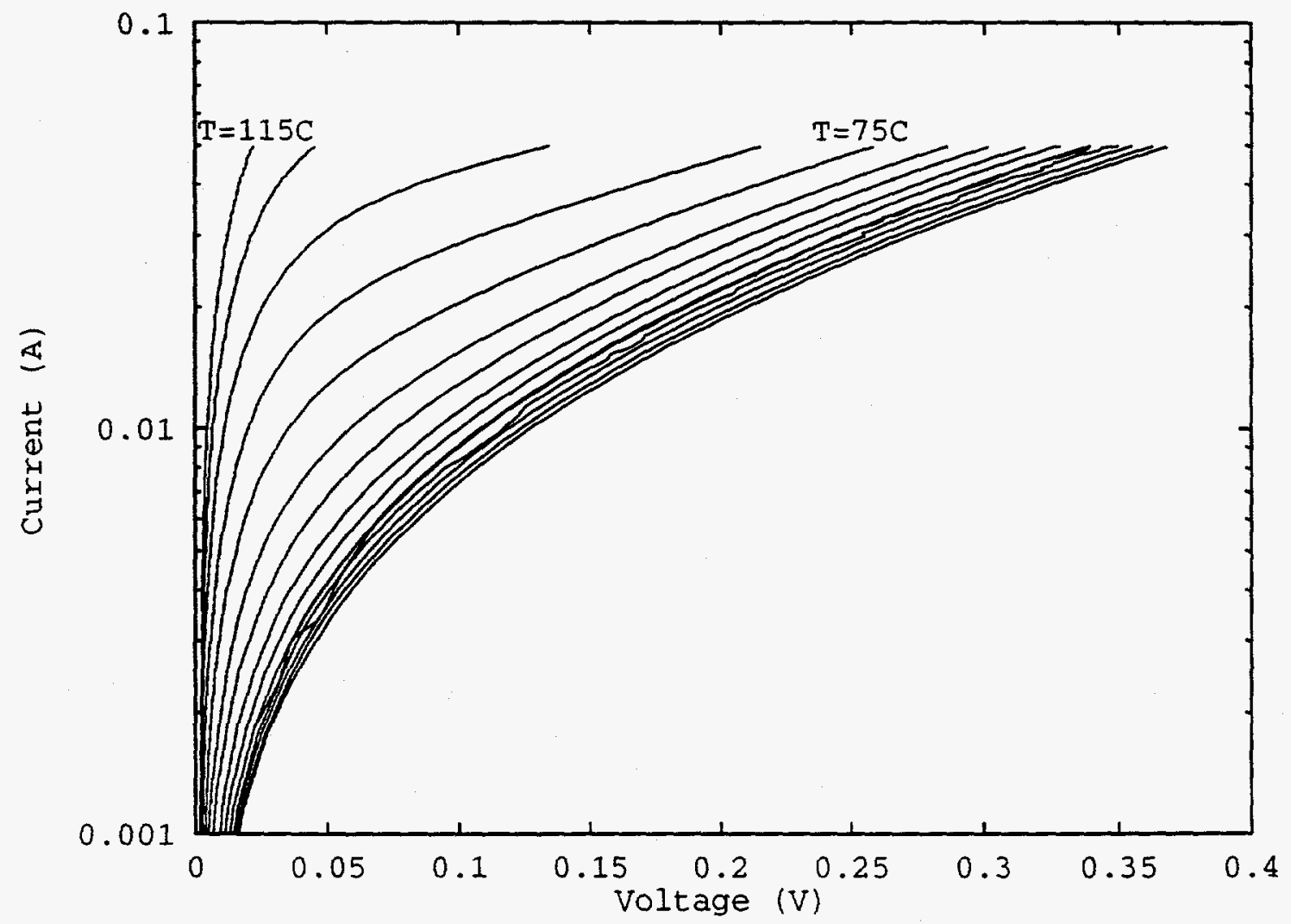

Figure 6: Temperature dependent reverse dark IV from $-15^{\circ} \mathrm{C}$ to $115^{\circ} \mathrm{C}$ at $10^{\circ} \mathrm{C}$ increments (device type 2 ) 


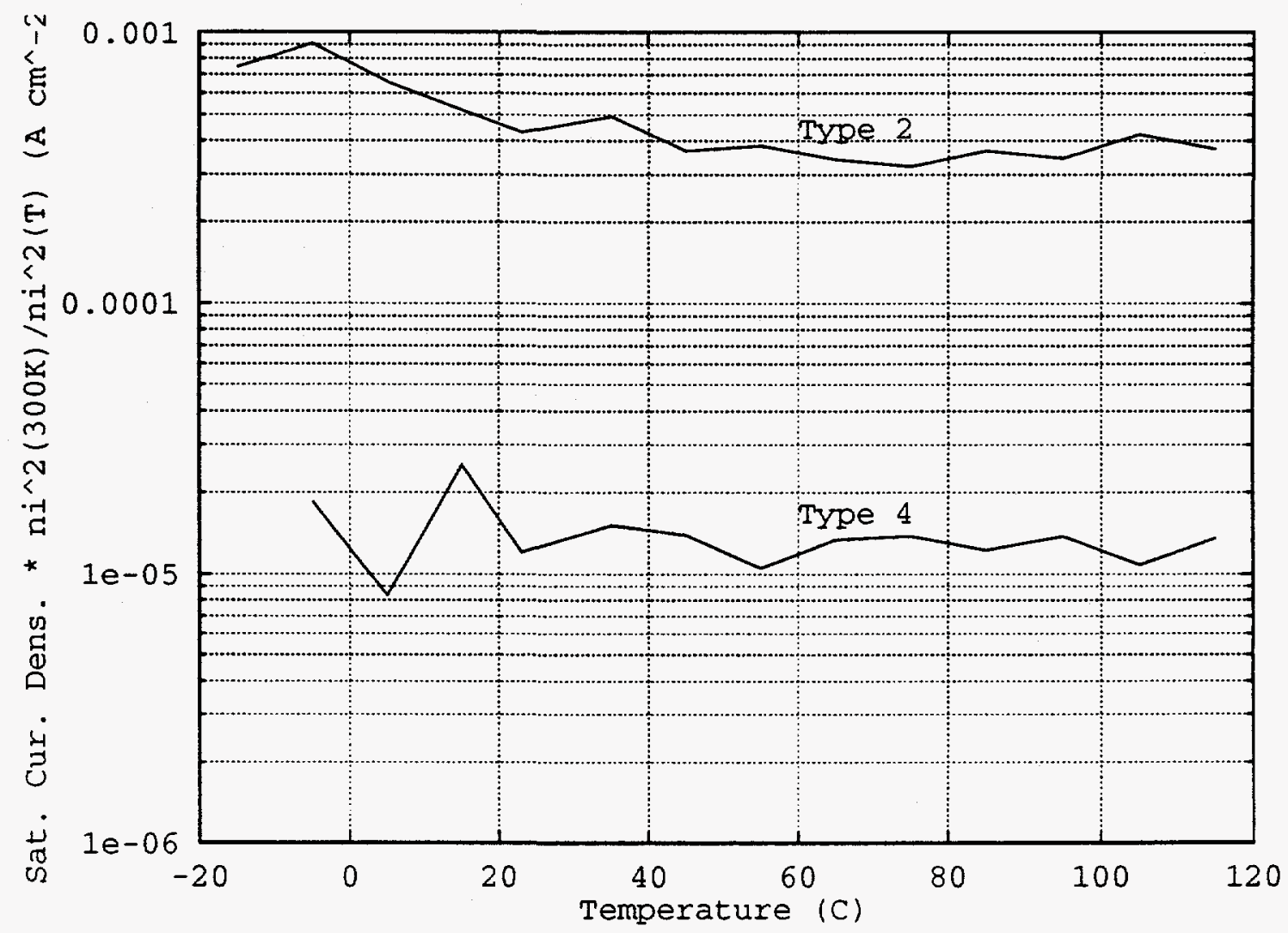

Figure 7: Temperature dependent forward dark IV saturation current densities normalized to $n_{i}^{2}$ (device types 2 and 4 ) 


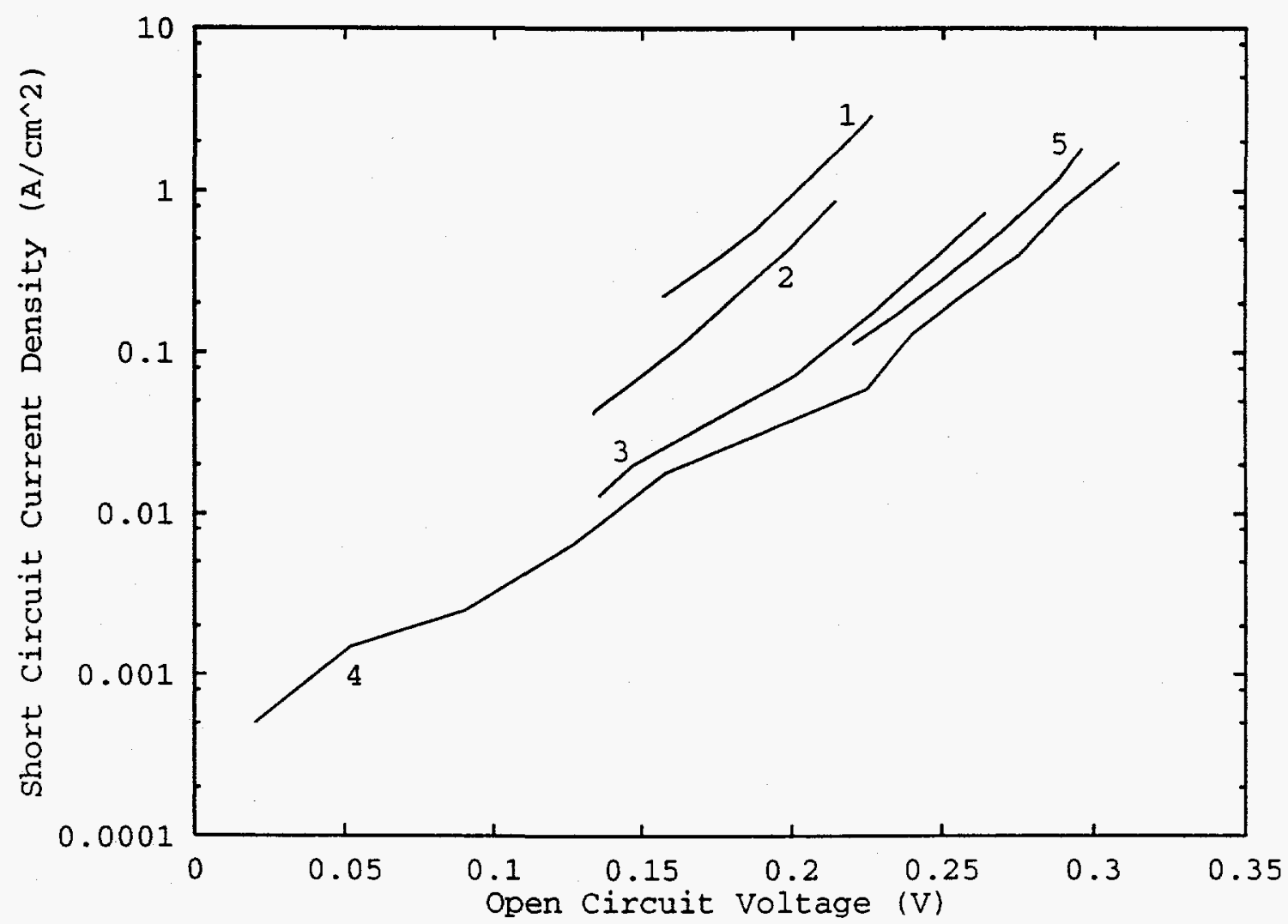

Figure 8: High intensity illumination characteristics for the 5 device types 